\title{
Overview
}


This chapter presents the key findings of the 2009 Living Costs and Food Survey (LCF), formerly the Expenditure and Food Survey. The chapter provides an overview of household income and expenditure, characterised by different household types and regions, as well as a summary of the ownership of a limited range of durable goods. All estimates in this publication have not been adjusted for inflation unless otherwise stated.

All of the tables (except Table 1.1) referred to in this chapter can be found in Appendix $A$ of the report (page 113).

\section{Household expenditure}

Table 1.1 shows total weekly household expenditure in the United Kingdom (UK) by the 12 Classification of Individual COnsumption by Purpose (COICOP)' categories. In 2009 average weekly household expenditure in the UK was $£ 455.00$, less than in 2008 when it was $£ 471.00$. As in previous years, spending was highest on transport at $£ 58.40$ per week. This was $£ 5.00$ less than in 2008 , a drop of 8 per cent.

Recreation and culture ( $£ 57.90$ per week) and housing, fuel and power ( $£ 57.30)$ were the next highest categories of expenditure, although the gap between these two categories narrowed between 2008 and 2009, with average spending on recreation and culture previously at $£ 60.10$ and average spending on housing, fuel and power at $£ 53.00$. The average weekly expenditure on food and non-alcoholic drinks in 2009 was $£ 52.20$.

\section{Table 1.1 Expenditure by COICOP category and total household expenditure, 2009}

\begin{tabular}{lr}
\hline COICOP category & £ per week \\
\hline Transport & 58.40 \\
Recreation and culture & 57.90 \\
Housing, fuel and power & 57.30 \\
Food and non-alcoholic drinks & 52.20 \\
Restaurants and hotels & 38.40 \\
Miscellaneous goods and services & 35.00 \\
Household goods and services & 27.90 \\
Clothing and footwear & 20.90 \\
Communication & 11.70 \\
Alcoholic drinks, tobacco and narcotics & 11.20 \\
Education & 7.00 \\
Health & 5.30 \\
\hline Total COICOP expenditure & 383.10 \\
\hline Other expenditure items & 71.80 \\
\hline Total expenditure & 455.00 \\
\hline
\end{tabular}

Totals may not add up due to the independent rounding of component categories 
Of the $£ 58.40$ spent on transport each week, half (50 per cent) was spent on the operation of personal transport (£29.30), see Table A1. This was a drop of 8 per cent on the previous year, in line with the overall drop observed in spending on transport. As in 2008 petrol, diesel and other motor oils (£19.20 per week) was the largest expenditure in the operation of personal transport category.

The expenditure within most categories under the heading transport fell between 2008 and 2009, including purchase of vehicles, which decreased from $£ 21.10$ to $£ 19.50$ per week in 2009 . In particular, households spent less on outright purchase of second hand cars or vans ( $£ 8.00$ per week compared to $£ 9.80$ per week in 2008). Households spent on average $£ 9.60$ per week on transport services, including rail, tube and bus fares, compared to $£ 10.50$ in 2008.

Approximately a third (32 per cent) of spending on recreation and culture ( $£ 18.70$ per week) was spent on recreational and cultural services; sports admissions, leisure class fees and equipment hire accounted for $£ 5.00$ per week; cinema, theatre and museums etc $£ 2.30$ per week; TV, video, satellite rental, cable subscriptions, TV licenses and internet $£ 5.90$ per week; and gambling payments $£ 4.10$ per week.

Spending on package holidays fell from $£ 14.70$ per week in 2008 to $£ 13.20$ in 2009 . Of this, $£ 12.30$ was spent on holidays abroad, $£ 1.30$ less than in 2008. Spending on audio-visual, photographic and information processing equipment ( $£ 7.00$ per week) and other recreational items and equipment, gardens and pets ( $£ 10.50$ per week) remained relatively constant. In particular, the average weekly spend on TV, video and computers remained at $£ 4.80$. (Table A1).

Of the $£ 52.20$ average weekly spend on food and non-alcoholic drinks, $£ 6.70$ was spent on fresh fruit and vegetables; $£ 2.90$ on fruit and $£ 3.80$ on vegetables; $£ 11.40$ was spent on meat, the highest proportion (47 per cent) of which was spent on other meat and meat preparations ( $£ 5.40$ per week); $£ 5.00$ was spent on bread, rice and cereals; $£ 3.20$ was spent on buns, cakes, biscuits, etc; and $£ 4.10$ was spent on non-alcoholic drinks (Table A1). Almost three-quarters (72 per cent, $£ 37.70$ per week) of food and non-alcoholic drinks were purchased from large supermarket chains (Table A3), an increase of $£ 1.20$ on the previous year.

Alcohol bought and consumed on licensed premises ( $£ 7.20$ per week) accounted for slightly more than half (55 per cent) of all expenditure on alcoholic drink ( $£ 14.00$ per week). Of the remaining $£ 6.80$ spent on alcohol, £4.60 was spent at large supermarket chains and $£ 2.20$ was spent at other off-licence outlets (Table A2).

\section{Household expenditure by income}

Household incomes have been ranked in ascending order and divided into decile groups in order to examine expenditure patterns between different income groups. Households with the smallest income lie in the first decile group and those with the largest income lie in the top (tenth) decile group. Average weekly household expenditure in 2009 ranged from $£ 162.70$ in the lowest of the 10 income decile groups to $£ 922.10$ in the highest (Figure 1.1, Table A6); expenditure in this highest decile was $£ 122.80$ lower than in 2008 . 


\section{Figure 1.1 Household expenditure by gross income decile group, 2009}

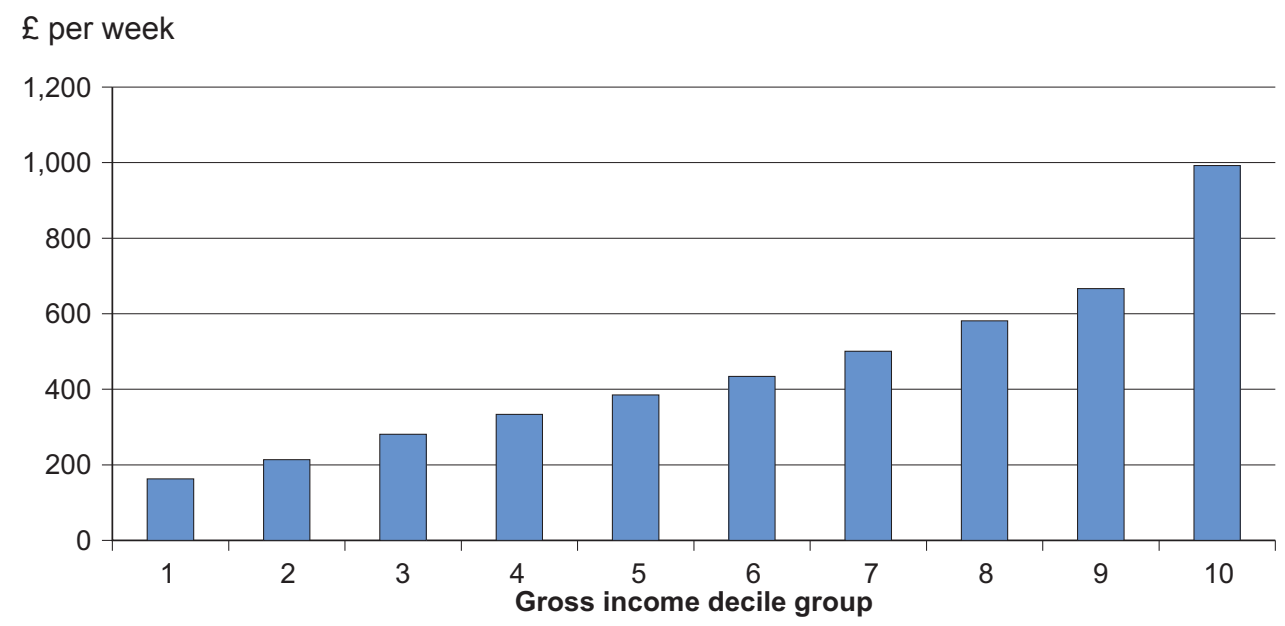

Households in the lowest income decile group spent a larger proportion of their total average weekly expenditure on housing, fuel and power (23 per cent), and food and non-alcoholic drinks (16 per cent), than those in the highest income decile group (8 per cent in both cases). Similarly, the lowest income decile group spent a larger proportion of expenditure on education (3 per cent) than some of the higher income decile groups (1 per cent in the seventh, eighth and ninth decile groups). However, households in the highest income decile group spent a greater proportion on transport (13 per cent) and recreation and culture (14 per cent) than those in the lowest income decile group (9 and 10 per cent respectively) (Table A7).

\section{Household expenditure by age}

Average weekly expenditure varied with the age of the household reference person (HRP). As in 2008, households whose HRP was aged 30 to 49 years had the highest average expenditure (£558.80 per week) while those with an HRP aged 75 years and over had the lowest average household expenditure ( $£ 236.40$ per week). It should be noted that households with an HRP aged 30 to 49 years contained an average of 2.9 people, whereas households with an HRP aged 75 years and over contained an average of 1.4 people (Table A11).

Spending on housing, fuel and power in households whose HRP was aged less than 30 years increased from $£ 76.20$ in 2008 to $£ 97.30$, an increase of 28 per cent (Table A11). This corresponds to 23 per cent of total household expenditure for households with a HRP aged less than 30 , whereas households with an HRP aged 75 years or over spent 17 per cent of their total household expenditure on housing, fuel and power (Table A12).

The proportion of expenditure spent on food and non-alcoholic drinks increased with age, from 9 per cent among households with an HRP aged less than 30 years to 16 per cent among households with an HRP aged 75 years and over.

The pattern of spending on restaurants and hotels, as a proportion of total expenditure, was relatively constant among age groups, with the percentage of total expenditure ranging from 9 per cent among households with an HRP aged between 30 and 64, to 6 per cent among households 
with an HRP aged 75 years and over (Table A12). When the amount spent is considered, household expenditure on restaurants and hotels was greatest in households with an HRP aged between 30 and 49 ( $£ 49.70$ per week), but much lower in households with HRP over 75 ( 113.10 per week). This compares with an average expenditure across all ages of $£ 38.40$ (Table A13).

Expenditure on recreation and culture, as a proportion of total spending, varied from 9 per cent among households with an HRP aged less than 30 years to a maximum of 14 per cent among households with an HRP aged 50 to 74 years (Table A12).

\section{Figure 1.2 Expenditure on selected items as a proportion of total spending by age of the HRP, 2009}

Per cent

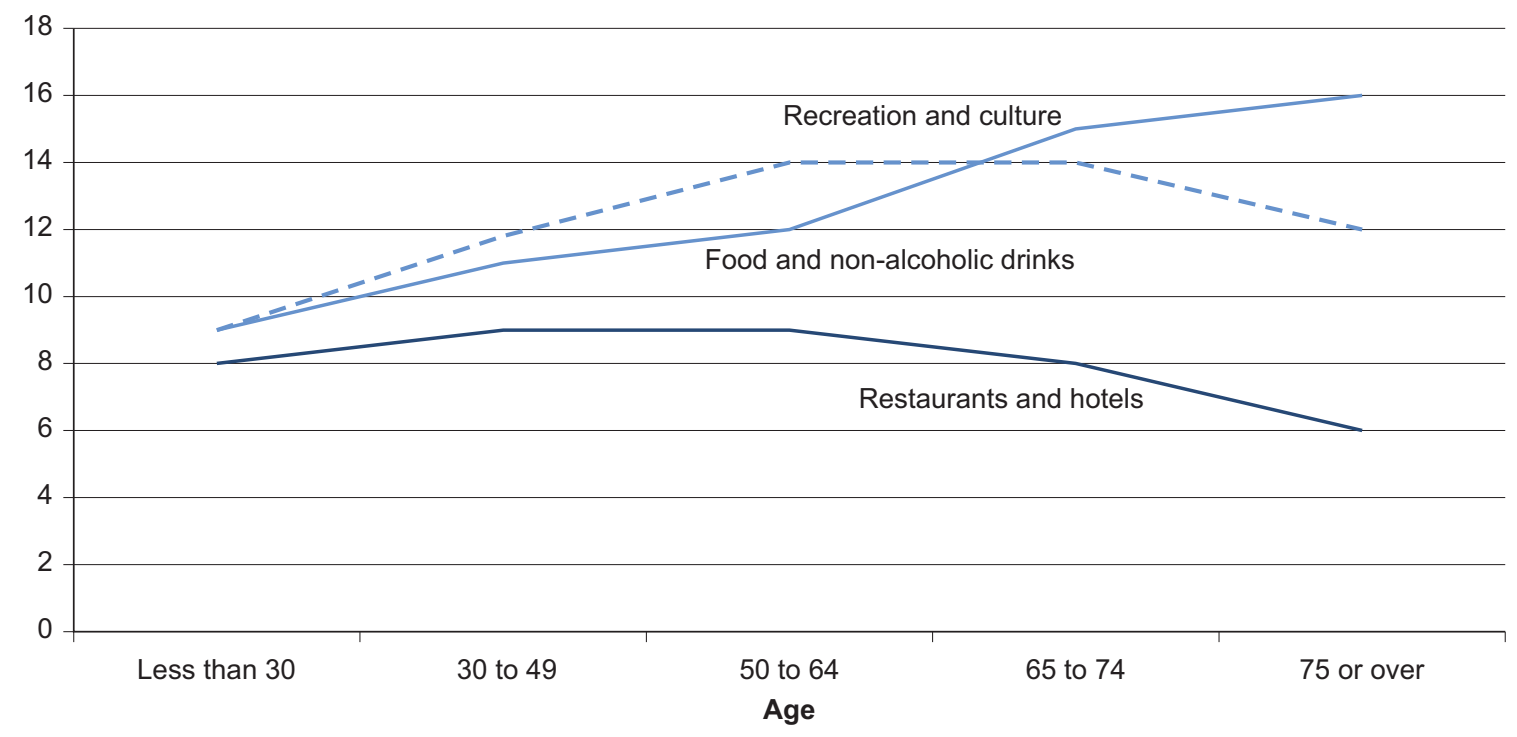

\section{Household expenditure by economic activity and socio-economic classification}

This analysis uses the National Statistics Socio-Economic Classification (NS-SEC), see Appendix B, page 133.

Household spending varied with the economic status of the HRP. The average weekly expenditure of households where the HRP was in employment ( $£ 568.50$ per week) was more than twice that of households where the HRP was unemployed ( $£ 229.00$ per week), and just under twice that of households where the HRP was economically inactive (£286.40 per week) (Table A19).

In households where the HRP was in employment, spending was greatest on transport ( $£ 77.00$ per week) and recreation and culture (£72.30 per week). Among households where the HRP was unemployed, spending on housing, fuel and power was greatest ( $£ 42.50$ per week), followed by food and non-alcoholic drinks (£31.90 per week) (Table A19).

Average weekly expenditure was highest among households where the HRP was in the 'large employers and higher managerial' occupational group, at $£ 877.70$ per week. An average weekly expenditure of $£ 398.90$ was recorded for households where the HRP was in a 'routine' occupation (Table A24). 


\section{Household expenditure by household composition}

Generally, household expenditure increased with the size of the household. Thus, average weekly household expenditure was lowest among retired one-person households who were mainly dependent on the state pension (£148.90) and highest among households containing three or more adults with children (£710.90) (Table A25).

\section{Household expenditure by region}

Overall, average household expenditure in the UK was $£ 461.70$ per week for the years 2007-09 combined. There were five regions in which expenditure over this period was higher than the UK average: expenditure was highest in London (552.30), followed by the South East (£523.90 per week), the East (£487.70), Northern Ireland (£485.80) and the South West (£474.10). Spending was lowest among households in the North East (£387.20), Wales (£396.10), and Yorkshire and the Humber (£400.70) (Figure 1.3, Table A35).

\section{Figure 1.3 Household expenditure by region, 2007 to 2009}

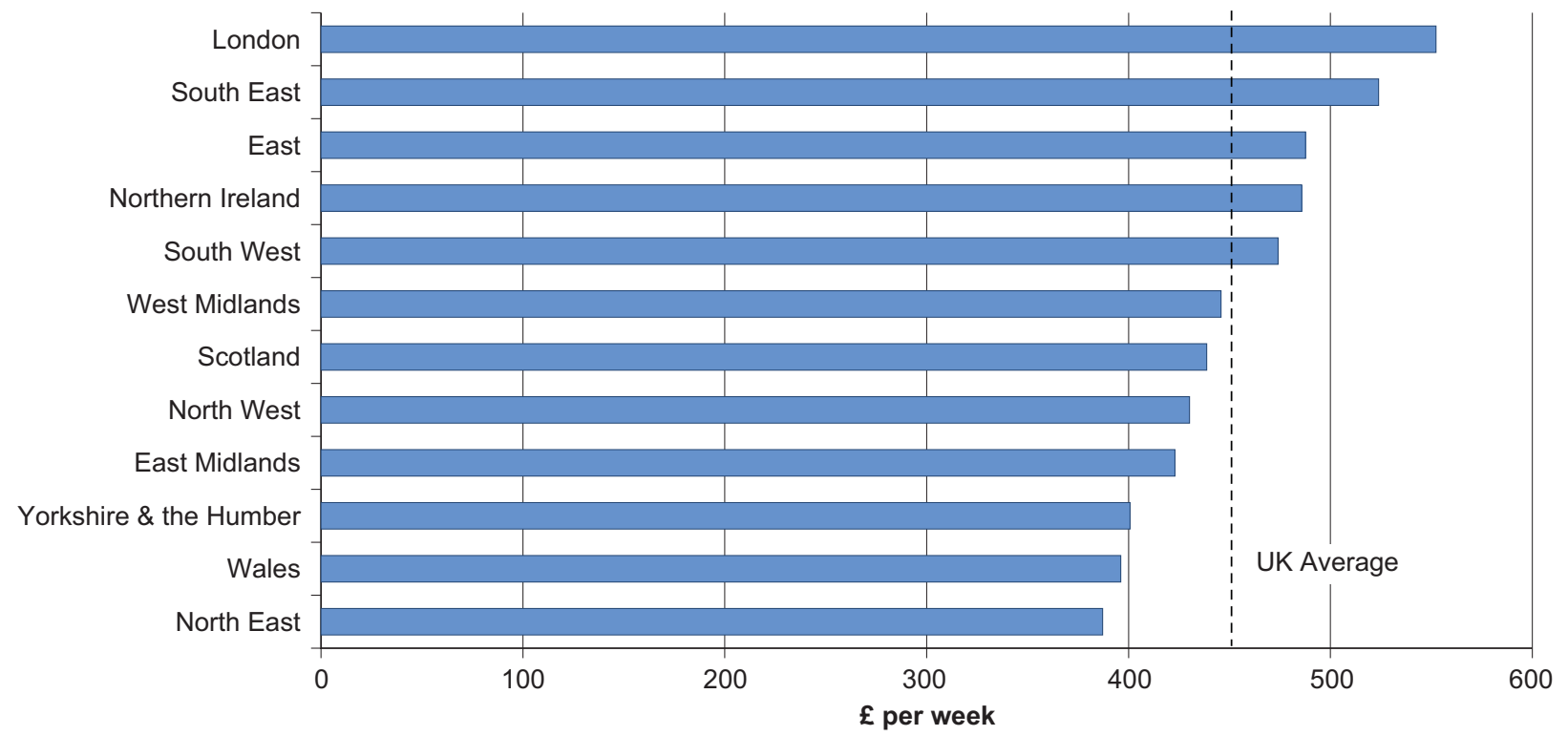

During the three-year period, 2007-2009, spending on transport was highest among households in the South East ( $£ 75.30$ per week) and lowest among those in the North East ( $£ 49.00$ per week). Households in London spent the most on housing, fuel and power ( $£ 80.10$ per week) compared with the UK national average of $£ 54.00$ per week (Table A37). Housing expenditure is looked at in more detail in chapter two.

Households in rural areas had higher overall expenditure ( $£ 500.00$ per week) than those in urban areas (£450.20 per week). This was reflected in expenditure on transport, where spending was highest ( $£ 75.70$ in rural areas and $£ 57.00$ in urban areas), and recreation and culture ( $£ 65.80$ in rural areas and $£ 56.40$ in urban areas). However, expenditure on housing, fuel and power was slightly higher in urban areas ( $£ 54.90$ per week) than in rural areas ( 552.00 per week) (Table A38). 


\section{Household income}

Income within the survey is defined as the gross weekly cash income current at the time of interview. Gross income includes salaries and wages, income from self employment, benefits and pensions. See Appendix B for further details on income.

Average gross weekly household income in the UK in 2009 was $£ 683.00, £ 30.00$ less than in 2008 (£713.00 per week). Besides wages and salaries (66 per cent), social security benefits formed the largest proportion of income (14 per cent), followed by self-employment income, and income from annuities and pensions at 8 per cent (Figure 1.4, Table A40).

\section{Figure 1.4 Percentage of gross weekly household income by source of income, 2009}

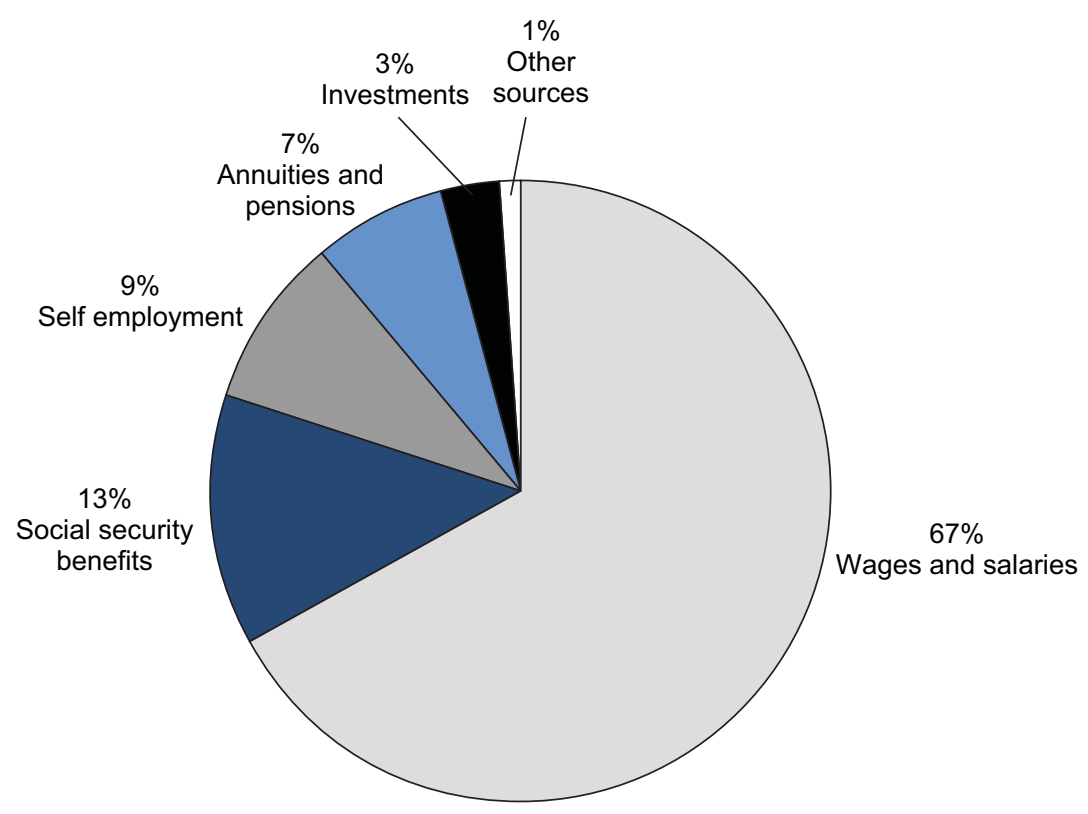

\section{Household income by age}

Households with an HRP aged 30 to 49 recorded the highest gross weekly income: $£ 873$ per week. Of this, 79 per cent was acquired from wages and salaries.

Households whose HRP was aged less than 30 years received the highest proportion of their average gross weekly income from wages and salaries (83 per cent), however this age group earned considerably less ( $£ 575$ per week) than households whose HRP was aged 30 to 64 years.

Households with a household reference person (HRP) aged less than 65 years of age had a higher average weekly gross income than those with an HRP aged 65 years and over. The lowest gross weekly income was recorded by households with an HRP aged 75 years or over ( $£ 331$ an increase of $£ 41.00$ from the previous year) with 54 per cent of their income gained through social security benefits. It is worth noting that households with an HRP aged 65 to 74 years and households with an HRP aged 75 years or over had a higher disposable (gross income minus direct taxes) proportion of their gross weekly income (91 and 93 per cent respectively) than households with an HRP aged less than 65 years (Table A41). 


\section{Household income by region}

There were three English regions that exceeded the 2007-2009 UK national average income of $£ 685$ per week. They were London (£940), the South East (£797) and the East (£732). Income was lowest among households in the North East (£561 per week) and Yorkshire and the Humber (£565 per week).

Among UK countries, households in England had the highest average gross weekly income (£698), whereas those in Wales had the lowest average income at £585 per week (Table A44).

\section{Household income by economic activity and socio-economic classification}

Households where the HRP was in the 'large employers and higher managerial' occupational group had an average gross weekly income of $£ 1,647$, almost three times the income of households where the HRP worked in a 'routine' occupation (£560). These incomes were acquired mainly from wages and salaries (87 and 82 per cent respectively).

Households with an HRP in the 'lower supervisory' occupational group received the highest proportion of their average gross weekly income (£738) from wages and salaries (89 per cent). By contrast, those households with an HRP in the 'long-term unemployed' occupational group obtained 85 per cent of their average gross weekly income (£204) from social security benefits (Table A46).

\section{Ownership of durable goods}

Overall, 75 per cent of households had a home computer and 71 per cent had an internet connection at home, an increase of 3 and 5 percentage points, respectively, from 2008 (Table A50). Among households in the highest income decile group, 98 per cent had a home computer and 97 per cent an internet connection, compared with only 38 and 30 per cent of households in the lowest income decile group. This does, however, represent a 5 percentage point increase in households with a home computer and a 4 percentage point increase on households with an internet connection in the lowest income decile group from 2008 (Table A51).

In general, households with children were more likely to have an internet connection than those without. Overall, 89 per cent of two-adult, non-retired households owned a home computer, with 86 per cent having an internet connection (Table A51).

Connection to the internet was lowest among households in Northern Ireland (57 per cent) and highest in the South East and London (both 72 per cent). Ownership of a mobile phone was lowest among households in Wales (49 per cent) and highest in the West Midlands and South West at 85 per cent (Table A53).

More than three-quarters (76 per cent) of all households owned a car or van, with 33 per cent owning two or more. Ownership of at least one car or van varied from 33 per cent in the lowest income decile, to 96 per cent in the highest (Table A52). 
Ownership of a car or van was highest among households in the East (83 per cent), the South West (82 per cent) and the South East (81 per cent), and lowest among households in London (64 per cent) and the North East (68 per cent) (Table A53).

1

From 2001-02, the Classification of Individual COnsumption by Purpose (COICOP) was introduced as a new coding frame for expenditure items. COICOP is the internationally agreed classification system for reporting household consumption expenditure. Total expenditure is made up from the total of the COICOP expenditure groups (1 to 12) plus 'Other expenditure items (13)'. Other expenditure items are those items excluded from the narrower COICOP classifications, such as mortgage interest payments, council tax, domestic rates, holiday spending, cash gifts and charitable donations. 